\title{
Development of an Hybrid Adaptive Neuro Fuzzy Controller for Surface Roughness (SR) prediction of Mild Steel during Turning
}

\author{
Ashwani Kharola \\ Institute of Technology Management (ITM) \\ Defence Research \& Development Organization (DRDO) \\ Mussoorie, Uttarakhand, India
}

\begin{abstract}
In this paper a new approach of designing an Adaptive neuro fuzzy inference system (ANFIS) controller for predicting Surface roughness (SR) during turning of mild steel has been illustrated. The influence of shape of Membership function (MF's) on controller's output has also been shown. The shape of the MF's considered for analysis were Triangular, Gbell and Trapezoidal. The input parameters considered in this study for predicting SR are namely Back rake angle, Side rake angle, Speed, Feed and Depth of cut. Modeling and simulation is done in Matlab-Simulink, results are shown with help of graphs and tables which validates the proposed model.
\end{abstract}

\section{KEYWORDS:}

ANFIS, Surface Roughness, Membership function, Data sets, Training, Testing.

\section{INTRODUCTION}

The manufacturing industries aims to produce products with low cost, high quality within minimum duration of time[1]. Turning is widely used for metal cutting and finishing of machined parts. The most crucial attribute which determine the quality of product is SR. A good surface finish results in better fatigue strength, corrosion resistance, creep life of the product, and also affects surface friction, wearing, light reflection, heat transmission etc[2]. Therefore it is necessary to specify desired value of SR and select appropriate process to reach the desired quality[3]. To achieve a good surface finish, an effective model is required for optimum machining. There are limited number of SR models and most of them are based on experiments conducted in laboratory[4].

ANFIS is one of recently developed soft-computing technique widely used for predicting SR during machining operations. A good amount of work has been done on ANFIS based turning during last few decades. Shinn Ying Ho et al.[5] proposed a modeling and prediction study of SR in turning operation using ANFIS. Shibendu Shekhar Roy[2] designed an ANFIS system for predicting SR using both triangular and bell membership function's. B. Sidda Reddy, J. Suresh Kumar and K. Vijaya Kumar Reddy [6] performed analysis of SR on CNC turning machine. They used carbide cutting tool for machining aluminium alloys. R.A. Mahdavinejad and H. Sharifi Bidgoli[7] optimized the SR parameters in dry turning using ANFIS. S. Harikrishna, K. Satyanarayana and K. Bapi Raju[1] proposed a SR model using ANFIS and Artificial neural networks (ANN) for machining aluminium alloy (AA 6351). Mehmet Adym et al.[8] performed DOI : 10.14810/ijmech.2015.4306 
prediction of SR and cutting zone temperature in dry turning of austentic stainless steel (AISI 304) using ANFIS and Particle swarm optimization (PSO) approach. Ankita Singh et al.[9] proposed an ANFIS based modeling for prediction of SR during machining of glass fiber reinforced epoxy composites. K. Sita Rama Raju, S. Rajesh and P. Rama Murty Raju [10] performed a comparison of SR in turning operation using ANFIS, Neural networks (NN's) and regression techniques. Grynal D' Mello and P. Srinivasa Pai[11] predicted SR in high speed machining using ANN and ANFIS techniques. In this research an ANFIS based approach for prediction of SR during turning of mild steel using high speed steel cutting tool is proposed. The data sets considered for the study[12] has been divided into training and testing sets. A total of 243 data sets were divided into 216 training data sets and 27 testing data sets. The input parameters considered for determining SR are Back rake angle $\left(^{\circ}\right)$, Side rake angle $\left({ }^{\circ}\right)$, Speed $(\mathrm{rpm})$, Feed (mm/rev) and Depth of cut $(\mathrm{mm})$.

\section{ANFIS Methodology}

ANFIS approach uses Takagi-Sugeno fuzzy inference system for its implementation[12]. It consists of two inputs $\mathrm{x}$ and $\mathrm{y}$ and one output $\mathrm{z}$ is shown in Figure 1.0

If $\mathrm{x}$ is $\mathrm{A} 1$ and $\mathrm{y}$ is $\mathrm{B} 1$, then $\mathrm{f}=\mathrm{px}+\mathrm{q} \mathrm{y}+\mathrm{r}$

If $x$ is $A 2$ and $y$ is $B 2$, then $f=p x+q y+r$

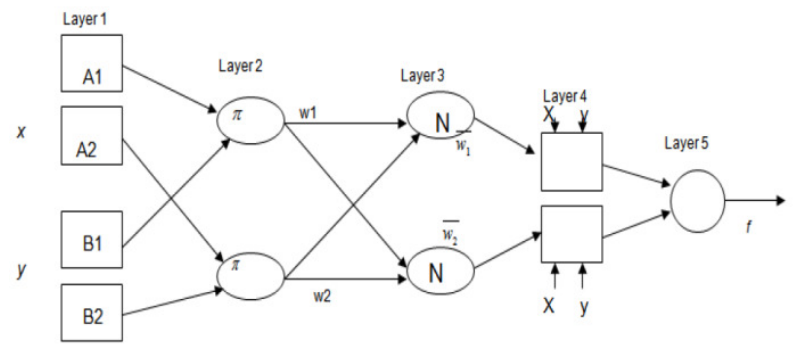

Figure 1. Basic ANFIS architecture

As shown in figure 1, a circle indicates a fixed node whereas a square indicates an adaptive node i.e. parameters are changed during adaptation or training. The ANFIS architecture consist of fuzzy layer, product layer, normalized layer, de-fuzzy layer and total output layer[2]. A flow chart for complete ANFIS procedure for SR prediction is shown in figure 1.1 
International Journal of Recent advances in Mechanical Engineering (IJMECH) Vol.4, No.3, August 2015

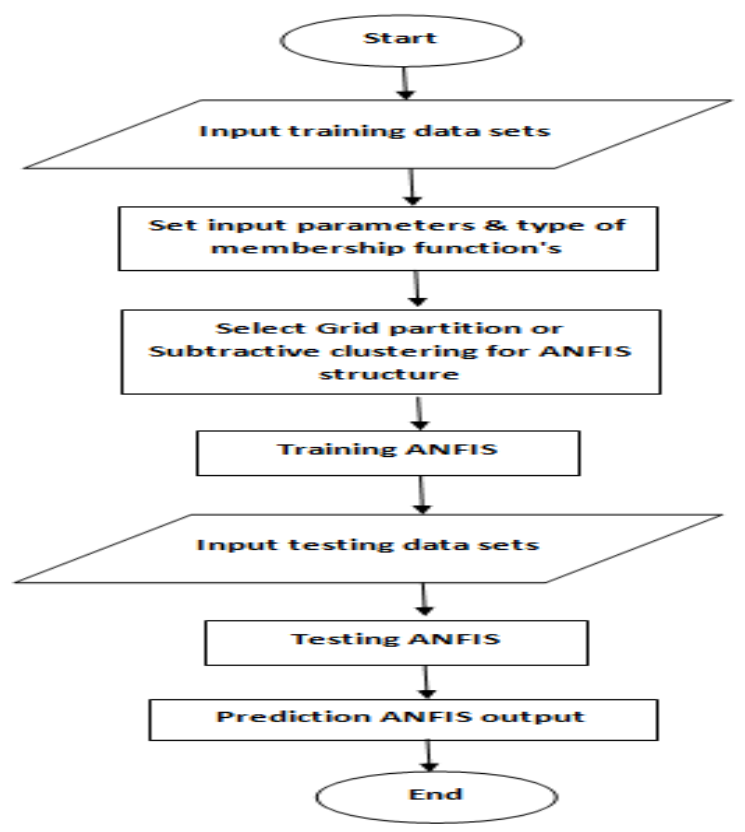

Figure 1.1 Flowchart for SR ANFIS prediction

\subsection{ANFIS Training}

In this study two different data sets were considered for training and testing of ANFIS controllers. All the data sets were then stored in workspace of Matlab ANFIS Toolbox. Firstly the training data is loaded from the workspace (refer Figure 1.2), and then using Grid Partition method initial FIS structure was generated (refer Figure 1.3).

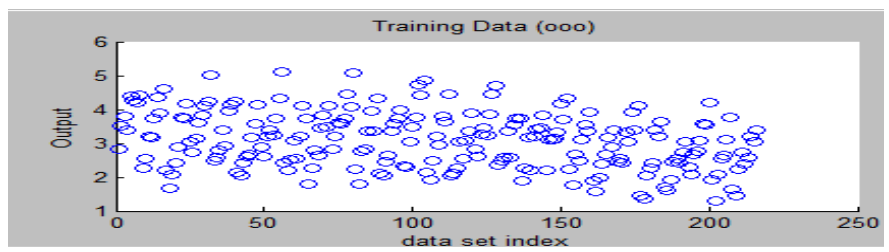

Figure 1.2 Loading of training data sets in ANFIS

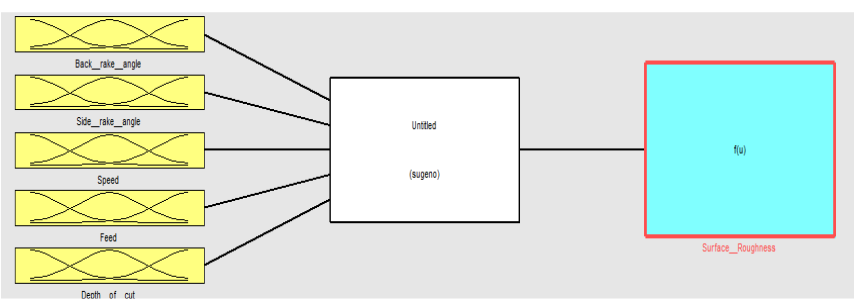

Figure 1.3 Initial FIS structure for ANFIS 
In this study three ANFIS controllers were designed using different MF's i.e. triangular, gbell and trapezoidal. The number of input MF's considered for each controller were 3. For training the error tolerance and number of epochs were set to 0 and 3 respectively. In this study a Hybrid approach which is a combination of least square method and back propagation was used for training of ANFIS controller. The error's obtained after training different ANFIS controller's are shown in table 1.

\begin{tabular}{|c|l|c|}
\hline S.No & \multicolumn{1}{|c|}{ Type of ANFIS Controller } & Error \\
\hline 1 & ANFIS Controller using triangular MF's & 0.044985 \\
\hline 2 & ANFIS Controller using gbell MF's & 0.044987 \\
\hline 3 & ANFIS Controller using trapezoidal MF's & 0.044986 \\
\hline
\end{tabular}

Table 1. Error's obtained after training in ANFIS using different MF's

\subsection{Designing of ANFIS controllers}

A 3-D view of surface viewers before training is shown in figure 1.4. The surface viewers obtained after training of ANFIS controller's are shown from figure 1. to figure 1.7.

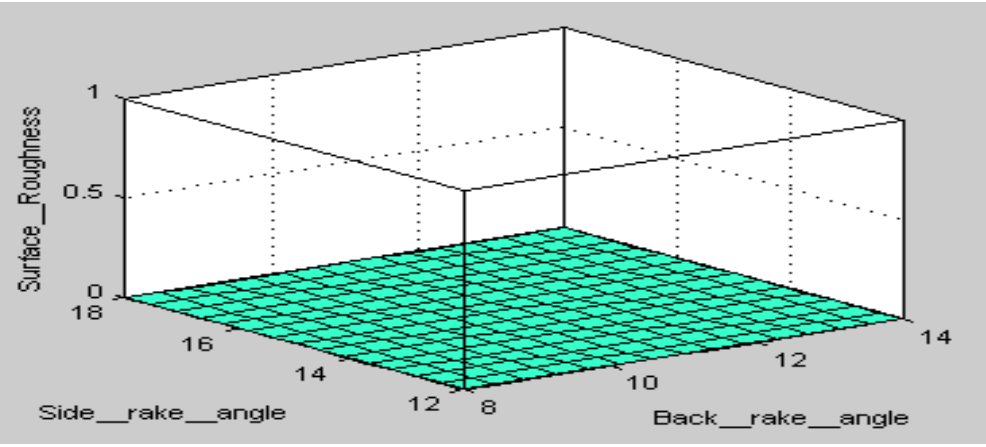

Figure 1.4 Surface viewer before training of ANFIS controller

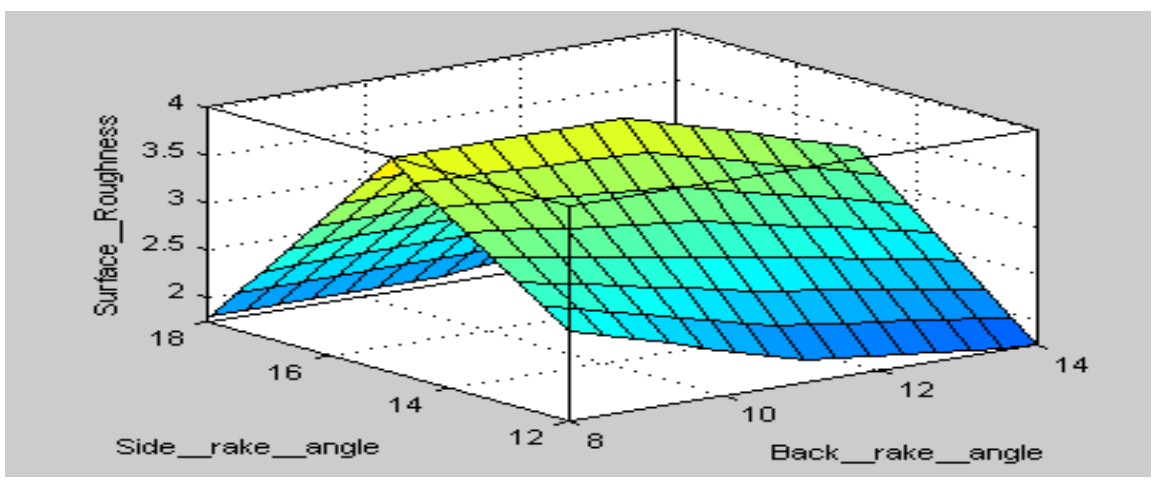

Figure 1.5 Surface viewer after training of triangular ANFIS controller 
International Journal of Recent advances in Mechanical Engineering (IJMECH) Vol.4, No.3, August 2015

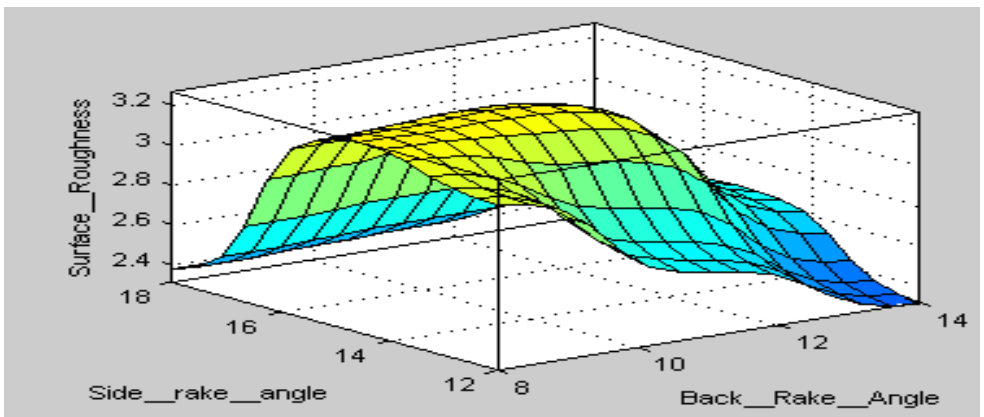

Figure 1.6 Surface viewer after training of gbell ANFIS controller

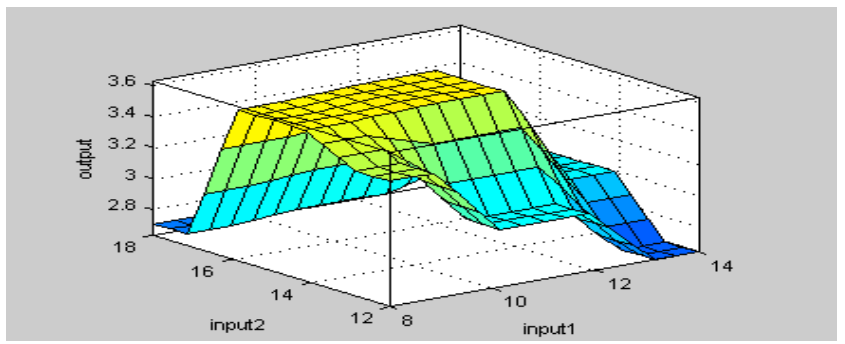

Figure 1.7 Surface viewer after training of trapezoidal ANFIS controller

\section{RESULTS AND COMPARISON}

A comparison of SR obtained from ANFIS and experiments for some of the training cases are shown in table 1.1

\begin{tabular}{|l|l|l|l|l|l|l|l|l|l|}
\hline S.No & $\begin{array}{l}\text { Back } \\
\text { rake } \\
(\circ)\end{array}$ & $\begin{array}{l}\text { Side } \\
\text { rake } \\
(\circ)\end{array}$ & $\begin{array}{l}\text { Speed } \\
(\mathbf{r p m})\end{array}$ & $\begin{array}{l}\text { Feed } \\
(\mathbf{m m} / \mathbf{r} \\
\text { ev) }\end{array}$ & $\begin{array}{l}\text { Depth } \\
\text { of cut } \\
(\mathbf{m m})\end{array}$ & $\begin{array}{l}\text { SR } \\
\text { Exp } \\
\cdot\end{array}$ & $\begin{array}{l}\text { SR } \\
\text { Tri. } \\
\text { ANFIS }\end{array}$ & $\begin{array}{l}\text { SR } \\
\text { Gbell } \\
\text { ANFI } \\
\text { S }\end{array}$ & $\begin{array}{l}\text { SR } \\
\text { Trap. } \\
\text { ANFIS }\end{array}$ \\
\hline 1 & 8 & 12 & 250 & 0.1 & 0.5 & $\begin{array}{l}2.8 \\
35\end{array}$ & 2.650 & 2.810 & 2.761 \\
\hline 2 & 8 & 12 & 250 & 0.5 & 1.5 & $\begin{array}{l}4.4 \\
10\end{array}$ & 4.654 & 4.512 & 4.614 \\
\hline 3 & 8 & 12 & 350 & 0.5 & 0.5 & $\begin{array}{l}4.3 \\
45\end{array}$ & 4.234 & 4.298 & 4.268 \\
\hline 4 & 8 & 15 & 350 & 0.1 & 1.0 & $\begin{array}{l}2.5 \\
70\end{array}$ & 2.616 & 2.598 & 2.690 \\
\hline 5 & 8 & 18 & 250 & 0.3 & 1.5 & $\begin{array}{l}3.7 \\
40\end{array}$ & 3.871 & 3.810 & 3.856 \\
\hline
\end{tabular}


Table 1.1 Comparison of SR values for training data sets

A comparison of SR obtained from ANFIS and experiments for some of the testing cases are shown in table 1.2

\begin{tabular}{|l|l|l|l|l|l|l|l|l|l|}
\hline S.No & $\begin{array}{l}\text { Back } \\
\text { rake } \\
(\circ)\end{array}$ & $\begin{array}{l}\text { Side } \\
\text { rake } \\
(\circ)\end{array}$ & $\begin{array}{l}\text { Speed } \\
(\mathbf{r p m})\end{array}$ & $\begin{array}{l}\text { Feed } \\
(\mathbf{m m} / \mathbf{r e v})\end{array}$ & $\begin{array}{l}\text { Depth } \\
\text { of cut } \\
(\mathbf{m m})\end{array}$ & $\begin{array}{l}\text { SR } \\
\text { Exp. }\end{array}$ & $\begin{array}{l}\text { SR } \\
\text { Tri. } \\
\text { ANFIS }\end{array}$ & $\begin{array}{l}\text { SR } \\
\text { Gbell } \\
\text { ANFIS }\end{array}$ & $\begin{array}{l}\text { SR } \\
\text { Trap. } \\
\text { ANFIS }\end{array}$ \\
\hline 1 & 8 & 12 & 250 & 0.1 & 1.0 & 3.190 & 2.786 & 3.045 & 2.898 \\
\hline 2 & 8 & 12 & 250 & 0.3 & 1.0 & 3.710 & 3.926 & 3.815 & 3.890 \\
\hline 3 & 8 & 15 & 550 & 0.5 & 0.5 & 3.870 & 3.657 & 3.806 & 3.734 \\
\hline 4 & 11 & 12 & 550 & 0.3 & 0.5 & 2.840 & 3.198 & 2.956 & 3.058 \\
\hline 5 & 11 & 15 & 350 & 0.3 & 1.5 & 3.220 & 3.498 & 3.389 & 3.426 \\
\hline
\end{tabular}

Table 1.2 Comparison of SR values for some of the testing data sets

\section{CONCLUSION}

An ANFIS controller to predict the values of SR during turning operation has been designed. The data sets were able to train all the controller's effectively. The training and testing results proves the validity of the proposed ANFIS approach. The gbell ANFIS controller shows better output response as compared to other two controllers. The error's obtained after training were low but further reduction in error could be obtained by increasing the number of MF's or by changing the shape of MF's i.e. Gaussian, sigmoid etc. Further, the application of ANFIS can be applied to other machining process including Electrical discharge machining (EDM), CNC lathes, milling etc.

\section{REFERENCES}

[1] S. Hari Krishna, K.Satyanarayana, K. Bapi Raju, "Surface roughness prediction model using ANN \& ANFIS", International Journal of Advanced Engineering Research and Studies (IJAERS), ISSN:2249 - 8974, Vol. I, Issue I, October-December, 2011/102-113.

[2] Shibendu Shekhar Roy, "Design of adaptive neuro-fuzzy inference system for predicting surface roughness in turning operation", Journal of Scientific \& Industrial Research, Vol. 64, Sept. 2005, pp 653-659.

[3] M. S. Lou, J.C. Chen, C. M. Li, "Surface roughness prediction for CNC end milling”, Journal of Industrial Technology, Vol.15, No.1, Nov 1998 - Jan 1999, 2-6.

[4] P. V. S. Suresh, P. V. Rao, S. G. Desmukh, "A genetic algorithm approach for optimization of the surface roughness prediction model”, International Journal of Mach Tools \& Manufacture, Vol. 42, 2002, 675-680.

[5] Shinn Ying Ho, Kuang Chyihee, Shih Shin Chen and Shimm Jang Ho, "Accurate modeling and prediction of surface roughness by computer vision in turning operation using an adaptive neuro fuzzy inference system", International Journal of Machine tools and Manufacture, Vol.42, Issue 13, October 2002, pp 1441-1446.

[6] B. Sidda Reddy, J. Suresh Kumar, K. Vijaya Kumar Reddy, "Prediction of Surface Roughness in Turning Using Adaptive Neuro-Fuzzy Inference System", Jordan Journal of Mechanical and Industrial Engineering(JJMIE), Volume 3, Number 4, December 2009, ISSN 1995-6665 Pages 252 259. 
[7] R.A. Mahdavinejad, H. Sharifi Bidgoli, "Optimization of surface roughness parameters in dry turning", Journal of Achievements in Materials and Manufacturing Engineering", Vol. 37, Issue 2, December 2009.

[8] Mehmet Aydin, Cihan Karakuzu, Mehmet Ucar, Abdulkadir Cengiz and Mehmet Ali Cavuslu, "Prediction of surface roughness and cutting zone temperature in dry turning processes of AISI304 stainless steel using ANFIS with PSO learning", International Journal of Advanced Manufacturing Technology, Springer-Verlag London 2012.

[9] Ankita Singh, Kumar Abhishek, Saurav Datta and Siba Sankar Mahapatra, "ANFIS based modeling for prediction of surface roughness during machining of glass fiber reinforced epoxy composites" International Journal of Materials, Manufacturing and Design (IJMMD), Academic Research Journals (India), Vol. 1, Num. 1, pp. 1-15, January-June 2012.

[10] K. Sita Rama Raju, S. Rajesh, P. Rama Murty Raju, "Prediction of surface roughness in turning process using soft computing techniques", International Journal of Applied Sciences and Engineering Research, Vol. 1, No. 2, ISSN 2277 - 9442, 2012.

[11] Grynal D’Mello and Srinivasa Pai, "Prediction of surface roughness in High Speed Machining: A comparison", International Journal of Research in Engineering and Technology (IJRET), Vol. 03, Special Issue. 03, ISSN: 2319-1163, May-2014.

[12] D.V.V. Krishan Prasad, "Influence of Cutting Parameters on Turning Process Using Anova Analysis", Research Journal of Engineering Sciences, Vol. 2(9), 1-6, ISSN 2278 - 9472 September (2013) .

[13] Cheun Chien Lee, Fuzzy Logic in Control System: Fuzzy Logic Controller - Part I \& 11, IEEE Transactions on System, Man, and Cybernetics, 20(2), (1990), 403-435.

[14] Sheng Qiang, Qing Zhou, X.Z.Gao, Shuanghe Yu, "ANFIS Controller for Double Inverted Pendulum," The IEEE International Conference on Industrial Informatics, July. 2008, pp. 475-479, 978-1-4244-2171-8/08/IEEE.2008 